\title{
Assessment of Tissue Eosinophilia as a Prognosticator in Oral Epithelial Dysplasia and Oral Squamous Cell Carcinoma-An Image Analysis Study
}

\author{
Megha Jain, ${ }^{1}$ Sowmya Kasetty, ${ }^{2}$ U. S. Sudheendra, ${ }^{3}$ Manisha Tijare, ${ }^{2}$ \\ Samar Khan, ${ }^{4}$ and Ami Desai ${ }^{2}$ \\ ${ }^{1}$ Department of Oral Pathology and Microbiology, Peoples Dental Academy, MIG, Block-C, Flat No. 14, PCMS Campus, \\ Peoples Hospital, Bhopal, Madhya Pradesh 462037, India \\ ${ }^{2}$ Department of Oral Pathology and Microbiology, Peoples College of Dental Sciences and Research Center, Bhopal, \\ Madhya Pradesh 462037, India \\ ${ }^{3}$ Department of Oral Pathology and Microbiology, Coorg Institute of Dental Sciences, Virajpet, Karnataka 571218, India \\ ${ }^{4}$ Department of Oral Pathology and Microbiology, Rishiraj Dental College, Bhopal, Madhya Pradesh 462036, India
}

Correspondence should be addressed to Megha Jain; megha.vipin12@gmail.com

Received 30 October 2013; Accepted 13 January 2014; Published 19 February 2014

Academic Editor: Luigi M. Terracciano

Copyright (C) 2014 Megha Jain et al. This is an open access article distributed under the Creative Commons Attribution License, which permits unrestricted use, distribution, and reproduction in any medium, provided the original work is properly cited.

Association of tissue eosinophilia with oral squamous cell carcinoma has shown variable results ranging from favourable to unfavourable or even having no influence on prognosis. Also, very few studies have been done to know the role of eosinophils in premalignancy. So the present study investigated role of eosinophilic infiltration in oral precancer and cancer and its possible use as a prognosticator. 60 histopathologically proven cases $(20$ cases each of metastatic and nonmetastatic oral squamous cell carcinoma and oral leukoplakia with dysplasia of various grades) were included. Congo red is used as a special stain for eosinophils. Each specimen slide was viewed under high power in 10 consecutive microscopic fields for counting of eosinophils. As a result, a significant increase in eosinophil count was found in oral carcinomas compared to dysplasia. Nonmetastatic cases showed higher counts than metastatic carcinomas. So, it is concluded that eosinophilia is a favourable histopathological prognostic factor in oral cancer. Moreover, higher eosinophil counts in carcinoma group compared to dysplasia group proved that they might have a role in stromal invasion thus suggesting that quantitative assessment of tissue eosinophilia should become a part of the routine histopathological diagnosis for oral precancer and OSCC.

\section{Introduction}

Eosinophils were first described by Wharton Jones in 1846 as "coarse granular cells" and later by Paul Ehrlich in 1880 as "eosinophils" [1]. Eosinophils are characterised by presence of abundant cytoplasm with coarse reflective granules [2] and are distinguished by their tinctorial properties showing bright red staining with acid aniline dyes [3]. Eosinophils are pleiotropic, multifunctional leucocytes and play an important role in health and disease. They are involved in initiation and propagation of diverse inflammatory responses including parasitic helminth, bacterial and viral infections, tissue injury, and allergic diseases as well as modulators of innate and adaptive immunity [4]. Extensive tissue eosinophilia has also been described in many cancers including oral squamous cell carcinoma [5].

Tumor-associated tissue eosinophilia (TATE) is defined as "eosinophilic stromal infiltration of a tumor not associated with tumor necrosis or ulceration." It was first described by Przewoski in 1896 in carcinoma of cervix [6]. It is characterised by the presence of eosinophils as a component of peritumoral and intratumoral inflammatory infiltrate [7, 8]. TATE in malignancies is associated with different sites such as nasopharynx [6,9], larynx [10,11], esophagus [12], colon [13, 14], cervix [15], external genitalia [16], skin [17], gastrointestinal tract [18], and oral cavity $[7,8,16,19-27]$. 
Eosinophils are hypothesized to have direct tumoricidal activity associated with release of cytotoxic proteins and also act indirectly by enhancing the permeability into tumor cells facilitating penetration of tumor-killing cytokines. Additionally, the eosinophils may promote tumor angiogenesis by the production of several angiogenic factors. These cells also contain preformed matrix metalloproteinases (MMP) such as MMP-9 as well as their inhibitors TIMP-1 and TIMP-2 indicating that they can also modulate extracellular matrix formation. A highly potent and selective eosinophil chemoattractant, eotaxin, mainly derived from tumor-associated eosinophils is partly involved in eosinophils chemotaxis to the tumour [5]. Likewise, mast cells secrete histamine and eosinophil chemoattractant factor (ECF) which further attract eosinophils in tissues [27].

Correlation of tissue eosinophilia with prognosis has shown variable results in oral squamous cell carcinoma. It has been related to a favourable and $[7,10,19,20]$ to an unfavourable $[15,21]$ prognosis or even having no influence on patient outcome $[6,24]$.

Very few studies have been conducted to know the role of eosinophils in premalignancy. Although, certain studies have compared eosinophil counts between in situ neoplastic lesions and invasive neoplastic lesions with higher counts in latter thus suggesting that elevated eosinophil counts are a histopathological marker associated with stromal invasion $[11,22]$.

Although intact eosinophils can be easily identified in tissue sections that are stained with hematoxylin and eosin staining, sometimes these granulocytes assume an uncommon morphology making their recognition difficult in routinely stained sections. In such situations, special technique like autofluorescence or immunohistochemistry is needed to detect the presence of intact or degranulating eosinophils particularly in tumors $[3,28]$. Moreover special stains like Congo red and carbol chromotrope also proved to be a valuable diagnostic tool for detection of eosinophils because of their unique property to bind with eosinophils [26, 27].

So, the study was aimed to elucidate the role of eosinophilic infiltration in oral precancer and cancer and its possible use as a prognosticator in oral squamous cell carcinoma using Congo red stain.

\section{Materials and Methods}

After obtaining ethical clearance, 60 intraoral histopathologically proven cases (20 cases each of metastatic and nonmetastatic oral squamous cell carcinoma (OSCC) and oral leukoplakia with dysplasia of various grades) were included in the study (Table 1).

The haematoxylin and eosin stained sections of all cases were observed under microscope. To reduce the interobserver variability, stained sections were graded for dysplasia using Burkhart and Maerkar [29] grading system by four separate examiners and OSCC using Broders grading [30]. The grading was decided when at least three observers agreed on the same grade. For counting of eosinophils,
TABLE 1: Showing distribution of study sample.

\begin{tabular}{lcc}
\hline $\begin{array}{l}\text { Study } \\
\text { groups }\end{array}$ & $\begin{array}{c}\text { Description of } \\
\text { groups }\end{array}$ & Number of cases \\
\hline Group I & $\begin{array}{c}\text { Metastatic } \\
\text { OSCC }\end{array}$ & $\begin{array}{c}\mathbf{2 0} \\
\text { Well-differentiated squamous cell } \\
\text { carcinoma (WDSCC) }=05 \\
\text { Moderately differentiated squamous } \\
\text { cell carcinoma (MDSCC) }=15\end{array}$ \\
& & $\mathbf{2 0}$ \\
Group II & $\begin{array}{c}\text { Nonmetastatic } \\
\text { OSCC }\end{array}$ & WDSCC $=12$ \\
& & MDSCC $=08$ \\
Group III & Dysplasia & $\mathbf{2 0}$ \\
& & Mild dys $=12$ \\
& & Moderate dys $=04$ \\
Severe dys $=04$
\end{tabular}

Bold values indicate total no. of cases that is 20 (in each category).

$5 \mu \mathrm{m}$ formalin fixed paraffin embedded tissue sections were obtained and stained with Congo red stain.

2.1. Congo Red Staining Procedure. Firstly, sections were deparaffinized, hydrated through graded alcohols to water, and then placed in 1\% Congo red solution for 8 minutes followed by washing in water. Then differentiation was done in $2.5 \% \mathrm{KOH}$ solution by dipping once. Sections were counterstained with hematoxylin for 8 minutes then washed under running tap water. Differentiation was done in $1 \%$ acid alcohol by dipping once. Lastly, the sections were dehydrated through alcohol and cleared in xylene. Finally, sections were mounted with DPX.

2.2. Counting of Eosinophils and Acquiring Digital Images. Each specimen was viewed under high power (40x) microscopic field for counting of eosinophils. High power field diameter of microscope used was $0.5 \mathrm{~mm}$. In case of OSCC, invasive front region was chosen for eosinophils estimation. The eosinophils were counted in 10 consecutive high power fields (hpf) and recorded as eosinophils/10 hpf [13]. Areas of tumor necrosis and degenerated muscle tissue areas have been excluded. Figures 1, 2, and 3 show the associated eosinophils in metastatic and nonmetastatic OSCC and oral epithelial dysplasia, respectively.

2.3. Statistical Analysis. Data was transferred to the excel sheet followed by statistical analysis using unpaired $t$ test and analysis of variance (one way ANOVA) using SPSS software. A value of $P<0.05$ was considered statistically significant.

\section{Results}

3.1. Assessment of Eosinophils in Each Study Group. Comparison of eosinophil counts among different grades of dysplasia assessed by one way ANOVA did not revealed any statistical significance (Table 2 ).

Comparison of eosinophil count between OSCC and dysplasia assessed by unpaired $t$ test showed significant 


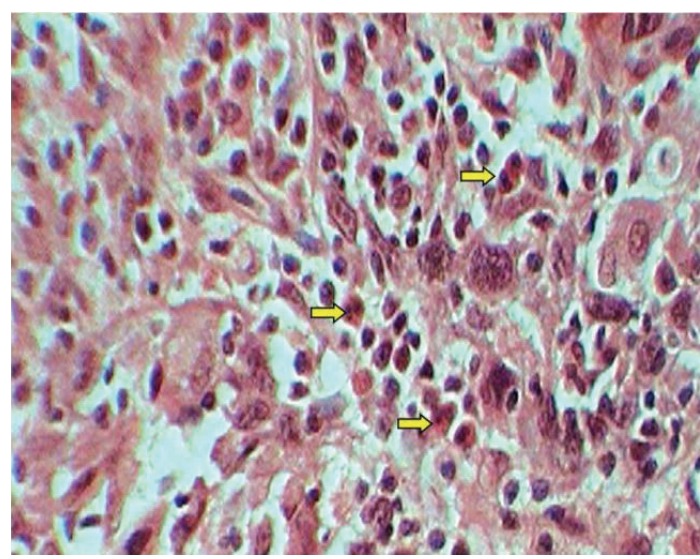

FIgURE 1: Showing eosinophils in Congo red stained sections of metastatic OSCC.

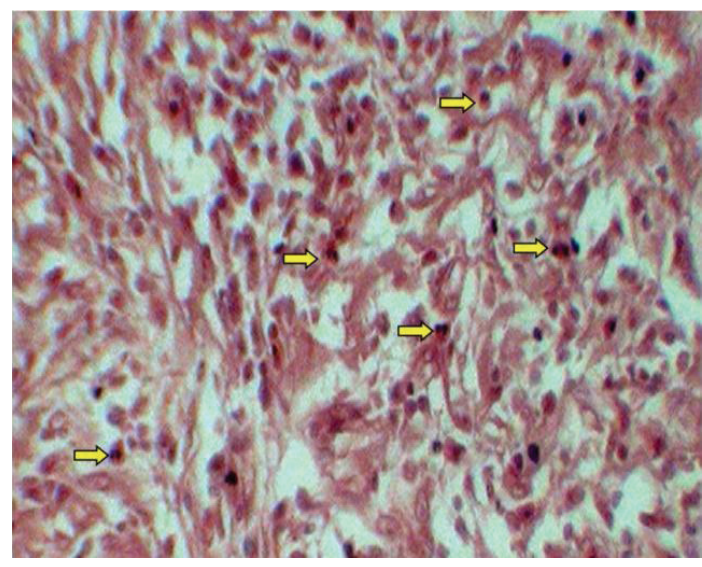

Figure 2: Showing eosinophils in Congo red stained sections of nonmetastatic OSCC.

increase in eosinophil count in OSCC compared to dysplasia (Table 3).

Comparison of eosinophil counts between metastatic (group I) and nonmetastatic (group II) OSCC assessed by unpaired $t$ test showed significantly raised eosinophil counts in nonmetastatic compared to metastatic OSCC (Table 4).

Among metastatic group, WDSCC has significantly higher eosinophilic counts compared to MDSCC, while in case of nonmetastatic group, the difference was statistically insignificant assessed by unpaired $t$ test (Table 5 ).

Among overall WDSCC and MDSCC, nonmetastatic group has higher eosinophil count compared to metastatic assessed by unpaired $t$ test (Table 6).

\section{Discussion}

The development of invasive cancer is not simply a result of genetic alterations within the tumor cell itself but is also associated with profound changes in host stromal, endothelial, and inflammatory/immune cells [8]. The peritumoral and intratumoral inflammatory infiltrates found in tumors have been considered as the host's immune response to

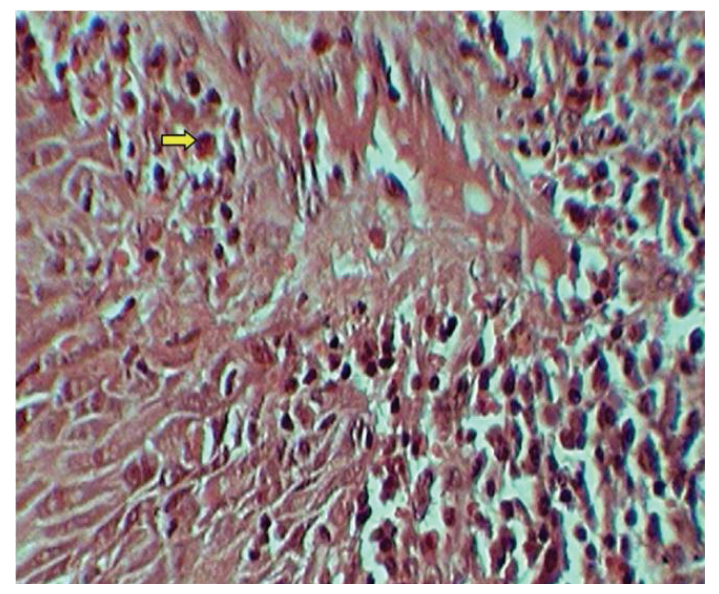

FIGURE 3: Showing eosinophils in Congo red stained sections of oral epithelial dysplasia.

TABLE 2: Depicting comparison of eosinophil counts among different grades of dysplasia.

\begin{tabular}{lccccc}
\hline Group & Grades & Mean & SD & $P$ value & Result \\
\hline Dysplasia & $\begin{array}{c}\text { Mild } \\
(n=12)\end{array}$ & 2.117 & 1.369 & & \\
$n=20$ & $\begin{array}{c}\text { Moderate } \\
(n=04)\end{array}$ & 2.850 & 1.085 & 0.652 & Nonsignificant \\
& $\begin{array}{c}\text { Severe } \\
(n=04)\end{array}$ & 2.325 & 1.537 & & \\
& & & & & \\
\hline
\end{tabular}

TABLE 3: Depicting comparison of eosinophil counts between OSCC (group I and II) and dysplasia.

\begin{tabular}{lcccc}
\hline Group & Mean & SD & $P$ value & Result \\
\hline $\begin{array}{l}\text { OSCC } \\
\text { (Group I and II) }\end{array}$ & 6.565 & 3.350 & $<0.0001$ & Significant \\
$n=40$ & & & & \\
\hline
\end{tabular}

TABle 4: Depicting comparison of eosinophil counts between metastatic (group I) and nonmetastatic (group II) OSCC.

\begin{tabular}{lcccc}
\hline Group & Mean & SD & $P$ value & Result \\
\hline $\begin{array}{l}\text { Group I } \\
\text { (metastatic) }\end{array}$ & 4.275 & 2.038 & & \\
$n=20$ & & & $<0.0001$ & Significant \\
$\begin{array}{l}\text { Group II } \\
\text { (nonmetastatic) }\end{array}$ & 8.855 & 2.800 & & \\
$n=20$ & & & & \\
\hline
\end{tabular}

the neoplasia $[7,8]$. The initial recruitment and activation of eosinophils towards the tumour microenvironment is a complex process that is mediated by inflammatory cytokines and chemokines and is principally related to Th2 response. IL- 4 and IL-13 are potent inducers of eotaxin chemokines that can explain the eosinophilia associated with Th2 responses. Eosinophil activation involves chemotactic factors like histamine and eosinophilic chemotactic factor A in mast cells, neutrophil peptides, eosinophil stimulator and promoter substances in lymphocytes, C5a complement, and eotaxin [2]. 
TABLE 5: Depicting comparison of eosinophil counts between different histological grades of metastatic (group I) and nonmetastatic OSCC (group II).

\begin{tabular}{|c|c|c|c|c|c|}
\hline Group & Grades & Mean & SD & $P$ value & Result \\
\hline \multirow{2}{*}{$\begin{array}{l}\text { Group I } \\
\text { (metastatic) } \\
n=20\end{array}$} & $\begin{array}{c}\text { WDSCC } \\
(n=5)\end{array}$ & 5.900 & 2.891 & \multirow{2}{*}{0.0355} & \multirow{2}{*}{ Significant } \\
\hline & $\begin{array}{l}\text { MDSCC } \\
(n=15)\end{array}$ & 3.733 & 1.412 & & \\
\hline \multirow{2}{*}{$\begin{array}{l}\text { Group II } \\
\text { (nonmetastatic) } \\
n=20\end{array}$} & $\begin{array}{l}\text { WDSCC } \\
(n=12)\end{array}$ & 8.208 & 2.239 & \multirow{2}{*}{0.2145} & \multirow{2}{*}{ Non-significant } \\
\hline & $\begin{array}{c}\text { MDSCC } \\
(n=8)\end{array}$ & 9.825 & 3.407 & & \\
\hline
\end{tabular}

TABLE 6: Depicting comparison of eosinophil counts between the same histological grades of metastatic (group I) and nonmetastatic OSCC (group II).

\begin{tabular}{|c|c|c|c|c|c|}
\hline Group & Grades & Mean & SD & $P$ value & Result \\
\hline $\begin{array}{l}\text { Group I } \\
\text { (metastatic) } \\
n=20\end{array}$ & $\begin{array}{c}\text { WDSCC } \\
(n=5)\end{array}$ & 5.900 & 2.891 & \multirow[b]{2}{*}{0.0075} & \multirow[b]{2}{*}{ Significant } \\
\hline $\begin{array}{l}\text { Group II } \\
\text { (nonmetastatic) } \\
n=20\end{array}$ & $\begin{array}{l}\text { WDSCC } \\
(n=12)\end{array}$ & 8.208 & 2.239 & & \\
\hline $\begin{array}{l}\text { Group I } \\
\text { (metastatic) } \\
n=20\end{array}$ & $\begin{array}{l}\text { MDSCC } \\
(n=15)\end{array}$ & 3.733 & 1.412 & \multirow[b]{2}{*}{$<0.0001$} & \multirow[b]{2}{*}{ Significant } \\
\hline $\begin{array}{l}\text { Group II } \\
\text { (nonmetastatic) } \\
n=20\end{array}$ & $\begin{array}{c}\text { MDSCC } \\
(n=8)\end{array}$ & 9.825 & 3.407 & & \\
\hline
\end{tabular}

Although eosinophils are commonly encountered in human cancer, their functional role in malignancy remains an ambiguity. The literature demonstrates a tendency to consider TATE as a favourable prognostic factor in head and neck squamous cell carcinoma (HNSCC), but TATE has also been related to a poorer prognosis or even to no influence on patients' outcome reflecting that this issue is still a matter of controversy $[7,8]$. Therefore, the present study was attempted to investigate the role of TATE in oral precancer and OSCC and whether it can be used as a predictive marker for OSCC.

In the present study, we have compared mean eosinophil count among mild, moderate, and severe dysplasia group but the difference was found to be statistically insignificant. Till now, none of the studies have considered grades of dysplasia as a parameter for counting of eosinophils and this needs further researches.

In our study, mean eosinophil count in OSCC group was found to be significantly higher than dysplasia group, suggesting that they might have a role in stromal invasion. The finding is in support with Alrawi et al. [22] who demonstrated elevated eosinophilic counts in invasive squamous cell carcinoma compared to noninvasive tumors of head and neck region. Similarly, findings by Falconieri et al. [23] suggested that SCC with eosinophil rich reactive inflammatory infiltrate is consistently associated with stromal invasion. Oliviera et al. [8] found that intense eosinophilia was strongly associated with advanced staged T3/T4. Said et al. [11] also reported elevated eosinophil counts in invasive laryngeal neoplasm compared to noninvasive (preinvasive) neoplastic lesions suggesting it as a morphologic feature associated with tumor invasion.

But the finding is in contrast to study by Moezzi et al. [13] who concluded that in the spectrum of colonic neoplasms, stromal eosinophilia is most prominent in adenomas and seems to decrease with progression through the adenomacarcinoma sequence. Kiziltaş et al. [14] also reported that that intensity of TE declined with increasing malignant potential of colonic epithelial neoplasms and may be used as diagnostic indicator.

In this study, mean eosinophil count in nonmetastatic OSCC group was found to be significantly higher than metastatic group indicating that eosinophils have a good prognostic role in OSCC. This finding is in accordance with Goldsmith et al. [19, 20] who found that TE was significantly associated with favourable outcome in SCC of head and neck and concluded that high grade TATE was the most influential among various histopathological variables affecting clinical outcome. Dorta et al. [7] found that intense tissue eosinophilia was associated with $72 \%$ of 5 -year disease-free cumulative survival whereas only $32 \%$ and $44 \%$ were associated with absent/mild and moderate tissue eosinophilia, respectively. Falconieri et al. [23] also confirmed that eosinophil rich SCC, although association with metastatic involvement of cervical lymph node seems to persue a less aggressive behaviour if compared with ordinary SCC. Debta et al. [26] found that increase infiltration of 
eosinophils and mast cells in OSCC were associated with favourable prognosis. Thompson et al. [10] also reported that TATE is associated with good term prognosis for laryngeal carcinoma. Ohashi et al. [12] found that cases of esophageal squamous cell carcinoma without lymph node metastasis had a significantly larger number of tumor-associated eosinophilia than those without lymph node metastasis.

But the studies in contrast to our result include those by Horiuchi et al. [21] whose findings revealed that the degree of eosinophil infiltrate and expression of HLA-DR antigen on tumor cell were significant prognostic factors associated with unfavourable prognosis in case of well differentiated OSCC. Alrawi et al. [22] also demonstrated that patients with high eosinophil indices had a statistically significant lower survival than those with lower eosinophil indices. Alkhabuli and High [31] found insignificant correlation between eosinophil density (ED) and survival and lymph node metastasis. Oliviera et al. [8] reported equivalent 5-year and 10-year overall survival and disease-free survival rates for both OSCC with intense and absent/mild tissue eosinophilia. Likewise, Tadbir et al. [24] concluded that TATE has no correlation with prognostic parameter in OSCC. Leighton et al. [6] assessed the presence of TATE in nasopharyngeal carcinoma and found that TATE was not significantly associated with local recurrence, distant metastasis, and survival.

As per the study, mean eosinophil count of WDSCC and MDSCC of no-metastatic group was significantly higher than metastatic group. However when mean eosinophil count within the group was compared, in metastatic group, WDSCC had significantly higher counts over MDSCC, but in nonmetastatic group, difference was found to be insignificant. So far, none of the studies have considered such categories of parameters but with regard to overall tumor differentiation few studies do exist. Iwasaki et al. [18] found a significant association between low degree of tumor cell differentiation and strong eosinophilic infiltration suggesting that some special histologic type of carcinoma may preferentially attract eosinophil into the lesion. Alkhabuli and High [31] did not find any correlation between eosinophil density and SCC differentiation in cases of SCC of tongue. Similarly, Tadbir et al. [24] failed to report any significant correlation between TATE and tumor differentiation in patients of OSCC. Also, Rahrotaban et al. [25] demonstrated no significant correlation between TATE and histopathologic grading, but it was lower in poorly differentiated group than in others in cases of HNSCC.

In conclusion, the present study assessed role of tissue eosinophilia as a prognosticator in oral precancer and OSCC (metastatic and nonmetastatic) and found tissue eosinophilia as a favourable histopathological prognostic factor in OSCC. In addition, we have found higher eosinophil counts in OSCC group compared to dysplasia group justifying that they might have a role in stromal invasion. So, the present study recommends that quantitative assessment of eosinophils should become a part of the routine histopathological diagnosis for oral precancer and OSCC. Also, one should be more cautious if higher eosinophil counts are evident in dysplastic lesions that prompt a thorough evaluation for invasiveness.

\section{Conflict of Interests}

The authors declare that there is no conflict of interests regarding the publication of this paper.

\section{References}

[1] D. Lowe, J. Jorizzo, and M. S. R. Hutt, "Tumour-associated eosinophilia: a review," Journal of Clinical Pathology, vol. 34, no. 12, pp. 1343-1348, 1981.

[2] T. R. Saraswathi, S. Nalinkumar, K. Ranganathan, R. Umadevi, and J. Elizabeth, "Eosinophils in health and disease: an overview," Journal of Oral and Maxillofacial Pathology, vol. 7, pp. 31-33, 2003.

[3] M. Samoszuk, "Eosinophils and human cancer," Histology and Histopathology, vol. 12, no. 3, pp. 807-812, 1997.

[4] S. P. Hogan, H. F. Rosenberg, R. Moqbel et al., "Eosinophils: biological properties and role in health and disease," Clinical and Experimental Allergy, vol. 38, no. 5, pp. 709-750, 2008.

[5] M. C. Pereira, D. T. Oliveira, and L. P. Kowalski, "The role of eosinophils and eosinophil cationic protein in oral cancer: a review," Archives of Oral Biology, vol. 56, no. 4, pp. 353-358, 2011.

[6] S. E. J. Leighton, J. G. C. Teo, S. F. Leung, A. Y. K. Cheung, J. C. K. Lee, and C. A. V. Hassel, "Prevalence and prognostic significance of tumor-associated tissue eosinophilia in nasopharyngeal carcinoma," Cancer, vol. 77, pp. 436-440, 1996.

[7] R. G. Dorta, G. Landman, L. P. Kowalski, J. R. P. Lauris, M. R. D. O. Latorre, and D. T. Oliveira, "Tumour-associated tissue eosinophilia as a prognostic factor in oral squamous cell carcinomas," Histopathology, vol. 41, no. 2, pp. 152-157, 2002.

[8] D. T. Oliveira, K. C. Tjioe, A. Assao et al., "Tissue eosinophilia and its association with tumoral invasion of oral cancer," International Journal of Surgical Pathology, vol. 17, no. 3, pp. 244-249, 2009.

[9] L.-M. Looi, “Tumor-associated tissue eosinophilia in nasopharyngeal carcinoma. A pathologic study of 422 primary and 138 metastatic tumors," Cancer, vol. 59, no. 3, pp. 466-470, 1987.

[10] A. C. Thompson, P. J. Bradley, and N. R. Griffin, "Tumorassociated tissue eosinophilia and long-term prognosis for carcinoma of the larynx," American Journal of Surgery, vol. 168, no. 5, pp. 469-471, 1994.

[11] M. Said, S. Wiseman, J. Yang et al., “Tissue eosinophilia: a morphologic marker for assessing stromal invasion in laryngeal squamous neoplasms," BMC Clinical Pathology, vol. 5, article 1, 2005.

[12] Y. Ohashi, S. Ishibashi, T. Suzuki et al., "Significance of tumor associated tissue eosinophilia and other inflammatory cell infiltrate in early esophageal squamous cell carcinoma," Anticancer Research, vol. 20, no. 5, pp. 3025-3030, 2000.

[13] J. Moezzi, N. Gopalswamy, R. J. Haas Jr., R. J. Markert, S. Suryaprasad, and M. S. Bhutani, "Stromal eosinophilia in colonic epithelial neoplasms," American Journal of Gastroenterology, vol. 95, no. 2, pp. 520-523, 2000.

[14] Ş. Kiziltaş, S. S. Ramadan, A. Topuzoğlu, and S. Küllü, "Does the severity of tissue eosinophilia of colonic neoplasms reflect their malignancy potential?" Turkish Journal of Gastroenterology, vol. 19, no. 4, pp. 239-244, 2008.

[15] W. J. Van Driel, P. C. W. Hogendoorn, F.-W. Jansen, A. H. Zwinderman, J. B. Trimbos, and G. J. Fleuren, "Tumor-associated eosinophilic infiltrate of cervical cancer is indicative for a less effective immune response," Human Pathology, vol. 27, no. 9, pp. 904-911, 1996. 
[16] D. Lowe and C. D. M. Fletcher, "Eosinophilia in squamous cell carcinoma of the oral cavity, external genitalia and anus. Clinical correlations," Histopathology, vol. 8, no. 4, pp. 627-632, 1984.

[17] D. Lowe, C. D. M. Fletcher, M. P. Shaw, and P. H. McKee, "Eosinophil infiltration in keratoacanthoma and squamous cell carcinoma of the skin," Histopathology, vol. 8, no. 4, pp. 619-625, 1984.

[18] K. Iwasaki, M. Torisu, and T. Fujimura, "Malignant tumor and eosinophils I. Prognostic significance in gastric cancer," Cancer, vol. 58, no. 6, pp. 1321-1327, 1986.

[19] M. M. Goldsmith, D. H. Cresson, and F. B. Askin, "Part II. The prognostic significance of stromal eosinophilia in head and neck cancer," Otolaryngology-Head and Neck Surgery, vol. 96, no. 4, pp. 319-324, 1987.

[20] M. M. Goldsmith, D. A. Belchis, D. H. Cresson, W. D. Merritt III, and F. B. Askin, "The importance of the eosinophil in head and neck cancer," Otolaryngology-Head and Neck Surgery, vol. 106, no. 1, pp. 27-33, 1992.

[21] K. Horiuchi, K. Mishima, M. Ohsawa, M. Sugimura, and K. Aozasa, "Prognostic factors for well-differentiated squamous cell carcinoma in the oral cavity with emphasis on immunohistochemical evaluation," Journal of Surgical Oncology, vol. 53, no. 2, pp. 92-96, 1993.

[22] S. J. Alrawi, D. Tan, D. L. Stoler et al., "Tissue eosinophilic infiltration: a useful marker for assessing stromal invasion, survival and locoregional recurrence in head and neck squamous neoplasia," Cancer Journal, vol. 11, no. 3, pp. 217-225, 2005.

[23] G. Falconieri, M. A. Luna, S. Pizzolitto, G. DeMaglio, V. Angione, and M. Rocco, "Eosinophil-rich squamous carcinoma of the oral cavity: a study of 13 cases and delineation of a possible new microscopic entity," Annals of Diagnostic Pathology, vol. 12, no. 5, pp. 322-327, 2008.

[24] A. A. Tadbir, M. J. Ashraf, and Y. Sardari, "Prognostic significance of stromal eosinophilic infiltration in oral squamous cell carcinoma," Journal of Craniofacial Surgery, vol. 20, no. 2, pp. 287-289, 2009.

[25] S. Rahrotaban, A. Khatibi, and A. Allami, "Assessment of tissue eosinophilia in head and neck squamous cell carcinoma by Luna staining," Oral Oncology, vol. 47, pp. S74-S156, 2011.

[26] P. Debta, F. M. Debta, M. Chaudhary, and V. Wadhwan, "Evaluation of prognostic significance of immunological cells (tissue eosinophil and mast cell) infiltration in oral squamous cell carcinoma," Journal of Cancer Science and Therapy, vol. 3, no. 8, pp. 201-204, 2011.

[27] P. Debta, F. M. Debta, M. Chaudhary, and A. Dani, "Evaluation of Infiltration of Immunological cell (tumour associated tissue eosinophils and mast cells) in oral squamous cell carcinoma by using special stains," British Journal of Medicine \& Medical Research, vol. 2, no. 1, pp. 75-85, 2012.

[28] S. C. M. Lorena, R. G. Dorta, G. Landman, S. Nonogaki, and D. T. Oliveira, "Morphometric analysis of the tumor associated tissue eosinophilia in the oral squamous cell carcinoma using different staining techniques," Histology and Histopathology, vol. 18, no. 3, pp. 709-713, 2003.

[29] A. Burkhart and R. A. Maerkar, Colour Atlas of Oral Cancer, Wolfe Medical Publications, Chicago, Ill, USA, 1981.

[30] G. Anneroth, J. Batsakis, and M. Luna, "Review of the literature and a recommended system of malignancy grading in oral squamous cell carcinomas," Scandinavian Journal of Dental Research, vol. 95, no. 3, pp. 229-249, 1987.
[31] J. O. Alkhabuli and A. S. High, "Significance of eosinophil counting in tumor associated tissue eosinophilia (TATE)," Oral Oncology, vol. 42, no. 8, pp. 849-850, 2006. 


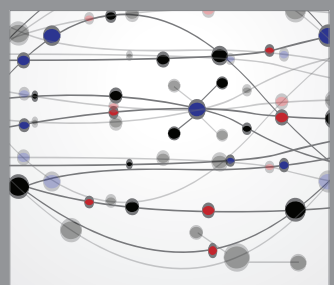

The Scientific World Journal
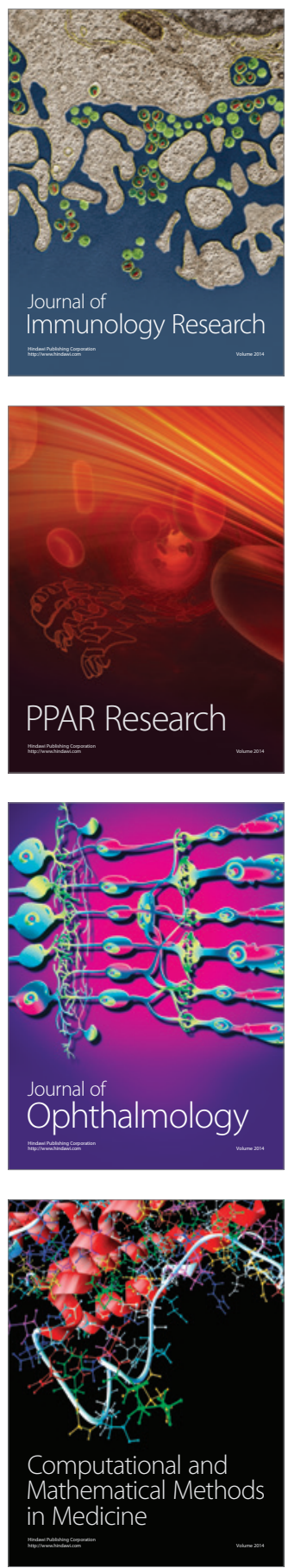

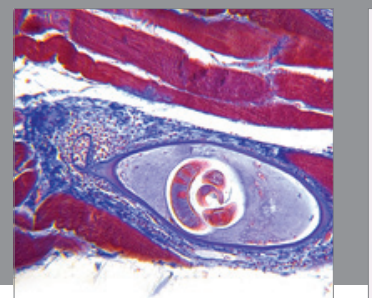

Gastroenterology

Research and Practice
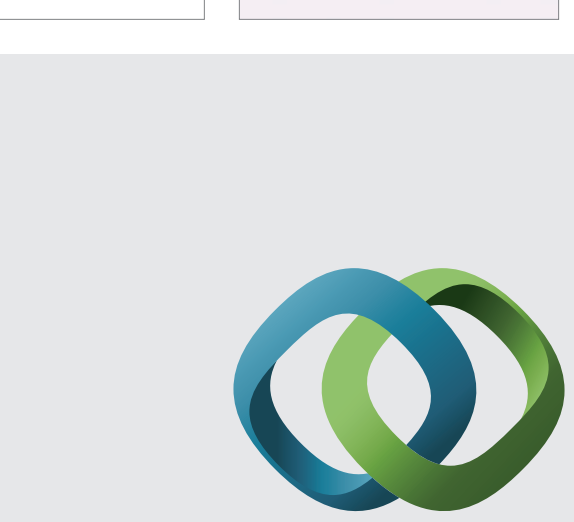

\section{Hindawi}

Submit your manuscripts at

http://www.hindawi.com
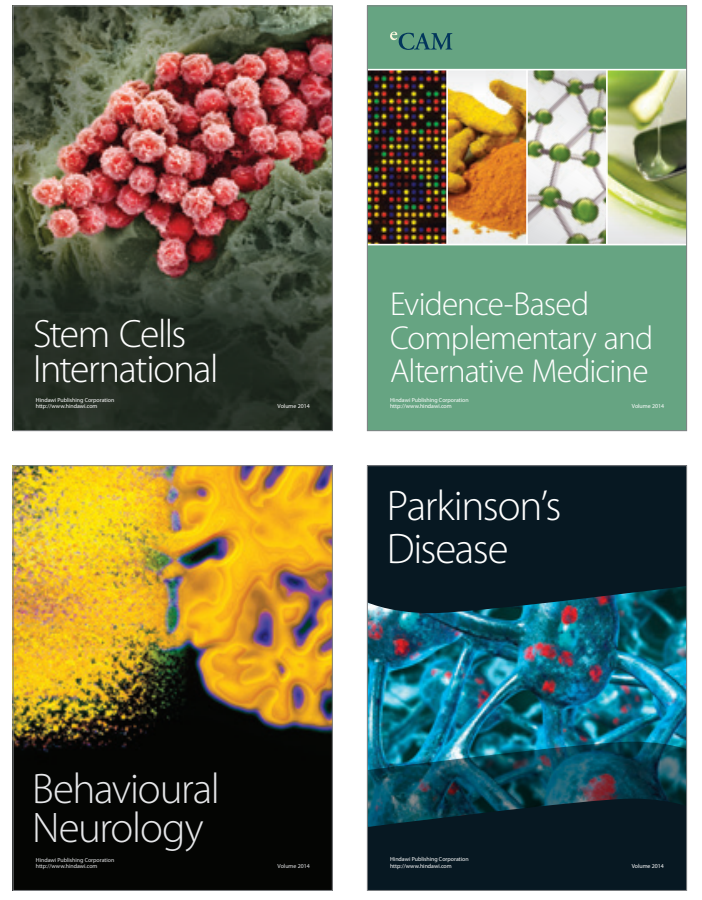
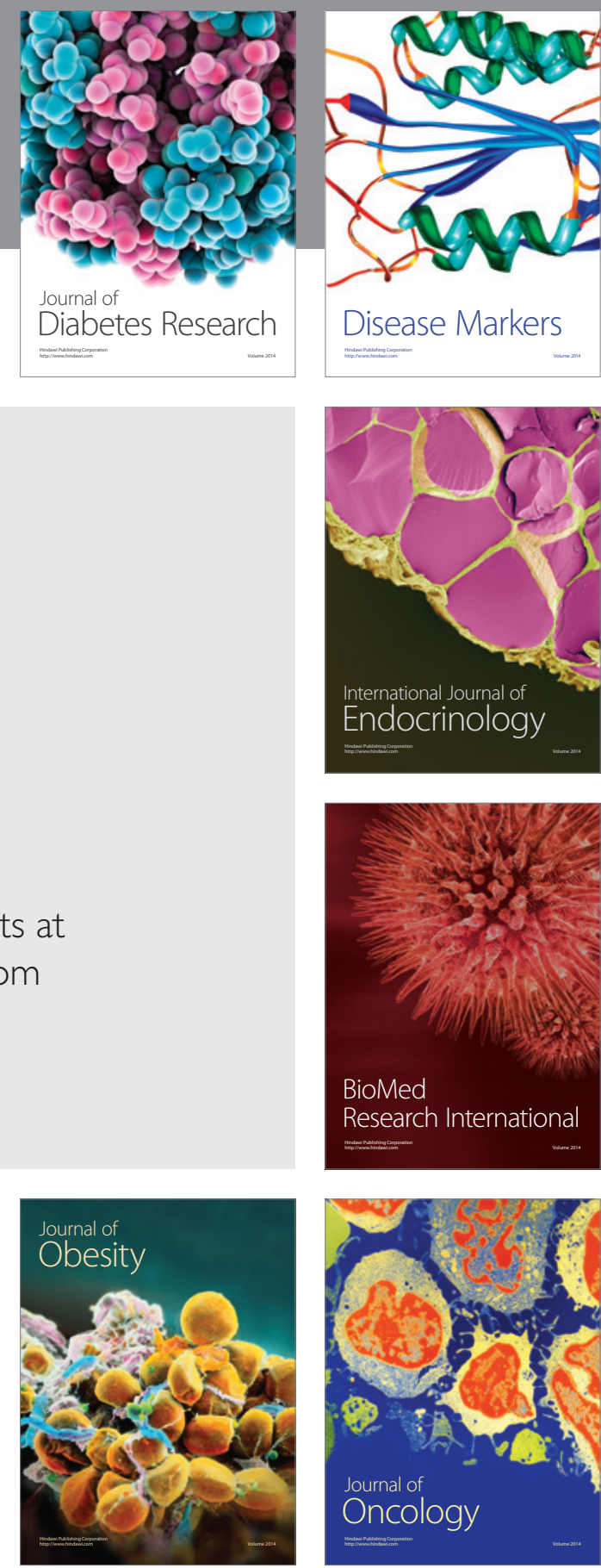

Disease Markers
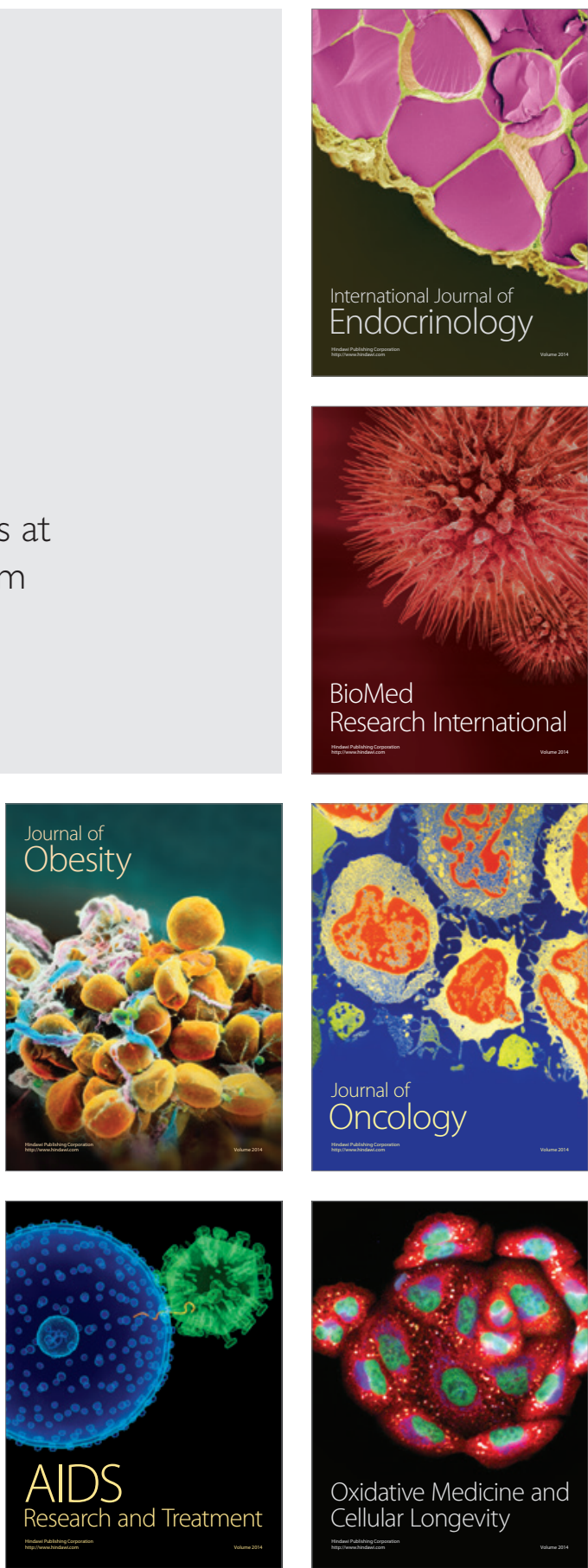